\title{
Synthesis and Analysis of Zirconium Titanate Thin Films by using Sol-Gel Method
}

\author{
Mohammad Hayath Rajvee 1,*iD, S.V. Jagadeesh Chandra 2,*iD, P. Rajesh Kumar ${ }^{1}$, \\ CH.V.V. Ramana ${ }^{3, *}$, Kalahasthi Neelama ${ }^{4}$, R. S. Dubey ${ }^{5}$ (ID
}

1 Department of Electronics and Communication Engineering, Andhra University College of Engineering (A), Andhra University, Visakhapatnam- 530003, Andhra Pradesh, India

2 Department of Electronics and Communication Engineering, Vignan Institute of Information Technology, Duvvada, Visakhapatnam- 530049, Andhra Pradesh, India

3 Department of Electrical and Electronics Engineering Science, Auckland Park Campus, University of Johannesburg, Johannesburg - 2006, South Africa

4 Department of Electrical and Electronics Engineering, VB Institute of Technology, Hyderabad, Telangana, India.

5 Advanced Research Laboratory for Nanomaterials and Devices, Department of Nanotechnology, Swarnandhra College of Engineering and Technology, Narsapur- 534280, West Godavari, Andhra Pradesh, India

* Correspondence: razwe2003@gmail.com (M.H.R.); svjchandra@gmail.com (S.V.J.C.); ramana6@gmail.com (C.H.V.V.R.);

Received: 20.12.2020; Revised: 15.01.2021; Accepted: 18.01.2021; Published: 31.01.2021

\begin{abstract}
Titanium-doped zirconium oxide (mixed high-k) has been used as the gate oxide layer for the future generation metal oxide semiconductor devices. This mixed high-k layer was prepared by using Sol-Gel based spin-coated method. This mixed high-k layer's chemical, structural, and initial electrical properties are investigated thoroughly. It is clearly confirmed that the suitable chemical composition and bond formation of the proposed mixed high-k layer from EDAX and FTIR analysis observations. The XRD spectra strengthened the presence of $\mathrm{ZrTiO}_{2}$. The measured dielectric constant of the proposed mixed high-k layer from the extracted C-V plots has been varying from 29.1 to 37.6 with respect to spin coating from 4000 to $6000 \mathrm{rpm}$. With lower spin rates, the leakage current is less.
\end{abstract}

Keywords: zirconium titanate; ZTO; ULSI; gate capacitors; high-k dielectrics.

(C) 2020 by the authors. This article is an open-access article distributed under the terms and conditions of the Creative Commons Attribution (CC BY) license (https://creativecommons.org/licenses/by/4.0/).

\section{Introduction}

The chemical composition of a proposed mixed thin film will have a major role in achieving a metal oxide semiconductor device's enhanced performance. Though there was rigorous research on various high dielectric (high-k) $\mathrm{TiO}_{2}, \mathrm{HfO}_{2}, \mathrm{Y}_{2} \mathrm{O}_{3}, \mathrm{La}_{2} \mathrm{O}_{3}, \mathrm{Gd}_{2} \mathrm{O}_{3}, \mathrm{Ta}_{2} \mathrm{O}_{5}$, $\mathrm{STO}, \mathrm{ZrO}_{2}, \mathrm{Al}_{2} \mathrm{O}_{3}$ monolayers, recently there is an intensive focus on the mixed high-k layers to replace the $\mathrm{SiO}_{2}$ [1-14] to have the bidirectional benefits on various physical and electrical applications. Among various high-k materials, $\mathrm{TiO}_{2}$ has a wide range of applications due to its physical and chemical properties. Its applications extend as a photocatalyst, solar cell, electrochromic devices, anti-reflection coating, sensors. Besides, $\mathrm{TiO}_{2}$ can also be used as reliable high-k material for DRAM applications because of its higher dielectric constant [1517]. $\mathrm{ZrO}_{2}$ has gained considerable attention during the recent decade because of its high bandgap of $\sim 5 \mathrm{eV}[18]$, large melting and boiling points, high crystallization temperature, high thermal stability, high dielectric constant [19-20]. 
On the other hand, when we use these two high-k materials individually, there was a problem with the electronic instabilities of zirconium oxide on Si substrate. Eventually, there would be an unstable interface at $\mathrm{ZrO}_{2} / \mathrm{Si}$ stacks [21-22], and $\mathrm{TiO}_{2} / \mathrm{Si}$ shows a high leakage current even at low temperature due to a very low conduction band offset value [23]. To accumulate the benefits of both oxide layers at a stretch in a single device, we are proposing interface engineering to support the chemical configuration and physical structure of the titanium doped zirconium oxide $\left(\mathrm{ZrTiO}_{2}\right)$ layers. $\mathrm{Zr}$-doped $\mathrm{TiO}_{2}$ thin films can be prepared by Plasma-assisted pulsed laser deposited [24], and atomic layer deposition [25], electron beam evaporation, DC magnetron sputtering, RF magnetron sputtering, and chemical deposition methods, namely chemical bath deposition, chemical spray pyrolysis method [26], sol-gel spin coating method [1-3,19,27-28]. We have chosen a sol-gel spin coating method in this work because it is an inexpensive method; coating can be carried out at room temperature over large areas under atmospheric pressure. The amorphous nature of the film prepared through the solgel method, offers a very low leakage current of 1.5×10-6 A/ $\mathrm{cm}^{2}$. Qian Zhang [1], and G. He et al., [2] reported that the crystallization temperature could be raised to $600^{\circ} \mathrm{C}$ by incorporating titanium into zirconium. The incorporation of Zirconium into $\mathrm{TiO}_{2}$ offers an increase in the conduction band offset to $\mathrm{Si}$ and subsequently reduced the leakage current density by approximately two orders than pure $\mathrm{TiO}_{2}$ thin films.

\section{Materials and Methods}

p-Type Si (100) wafers with a resistivity of 5-10 ohm-cm were used in this study. After removing the native oxide, $\mathrm{ZrTiO}_{2}$ films were deposited with a thickness of $40.0 \mathrm{~nm}, 41.20 \mathrm{~nm}$, and $44.28 \mathrm{~nm}$ were grown on the wafers using sol-gel based spin-coating technique at 4000 , 5000 , and $6000 \mathrm{rpm}$ for 30 Seconds with zirconium oxychloride octahydrate $\left(\mathrm{ZrOCl}_{2} .8 \mathrm{H}_{2} \mathrm{O}\right)$ and titanium tetrachloride $\left(\mathrm{TiCl}_{4}\right)$ precursors as the basic reactants. After each coating, the substrates were annealed at $200^{\circ} \mathrm{C}$ for 20 minutes. This process was repeated 10 times to achieve a considerable thickness of the coating. The physical thicknesses of the $\mathrm{ZrTiO}_{2}$ films were determined using ellipsometry studies. Thickness(tox $)$ and of the ZTO thin films have been measured with automatic angle spectroscopic ellipsometer [M2000VI] using multipoint measurement technique at the visible wavelength of $632.8 \mathrm{~nm}$. Topographic analysis of the films is carried out using FESEM[JEOL JSM-7100F], and compositional analysis is done with OXFORD's EDX tool connected to FESEM. X-ray diffraction data were collected with a Philips x'pert system using CuK $\alpha$ radiation $\left(\lambda=1.5418 \mathrm{~A}^{0}\right)$ at $45 \mathrm{KV}$ and step size of $0.008 \AA$. $\mathrm{TiCl}_{4}$ precursor was used as a dopant in the zirconium. A gel-like structure was formed upon the introduction of 2-Methoxy ethanol. All the chemicals were purchased from Sigma Aldrich (USA) and used without further purification or alteration. 0.62 grams of zirconium oxychloride octahydrate powder equivalent to 5 moles are mixed in $50 \mathrm{ml}$ of 2-methoxy ethanol using a magnetic stirrer for $5 \mathrm{~min}$ at 300rpm. Finally, $0.54 \mathrm{ml}$ of titanium tetrachloride is added to the above mixture and again mixed by the magnetic stirrer for $720 \mathrm{~min}$ at $400 \mathrm{rpm}$. After stirring the $\mathrm{ZrTiO}_{2}$ solution for 12 hours, it was filtered using a $0.22 \mu \mathrm{m}$ syringe filter to get a clear transparent solution.

All the as-deposited $\mathrm{ZrTiO}_{2}$ films were baked treated for $2 \mathrm{hrs}$ at $200^{\circ} \mathrm{C}$. After metallization (Contacts on both sides), though e-Beam evaporation, the samples are loaded into the furnace for baking at $200^{\circ} \mathrm{C}$ for $2 \mathrm{hrs} \mathrm{Al} / \mathrm{ZrTiO}_{2} / \mathrm{p}-\mathrm{Si}$ gate capacitor. 


\section{Results and Discussion}

Figure 1 shows the field emission scanning electron micrograph of the films formed at $4000 \mathrm{rpm}$. The film's topography showed a uniform coating made with the spin coating with less porosity and negligible cracks and delaminations on its surface. The other films formed at 5000 and $6000 \mathrm{rpm}$ (not shown here) also showed similar topography. Image is taken from FESEM at 650x magnification; over a surface of 10 $\mu \mathrm{m}$. FESEM enables obtaining chemical information from the specimen by using various techniques, including the X-ray energy dispersive spectrometer (EDS).

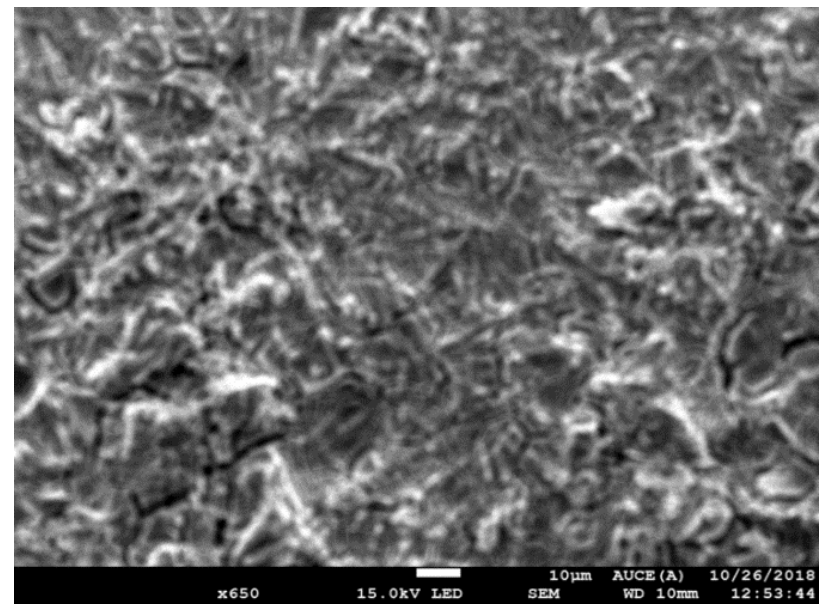

Figure 1. FESEM image of $\mathrm{ZrTiO} 2$ Thin Film.

The EDS spectrum, shown in figure 2. It has been obtained from FESEM through oxford's EDX attachment connected to it. The highest peak is shown in the spectrum shown as zirconium with 6.68 Weight $\%$. The titanium quantity is approximately half of zirconium, confirming the 1:2 molar ratio of titanium and zirconium. The quantity of oxygen (shown in table 1), is more because it contains oxygen in the thin film, substrate silicate oxygen, and film surface. The Quantitative representation of materials in the oxide layer is shown in Figure 3. EDX data is collected at a working distance of $10 \mathrm{~mm}$, a probe current of $8 \mathrm{~mA}$, and a maintained accelerating voltage of $10 \mathrm{KV}$. The numerical representation of the available major elements is shown in table 1.

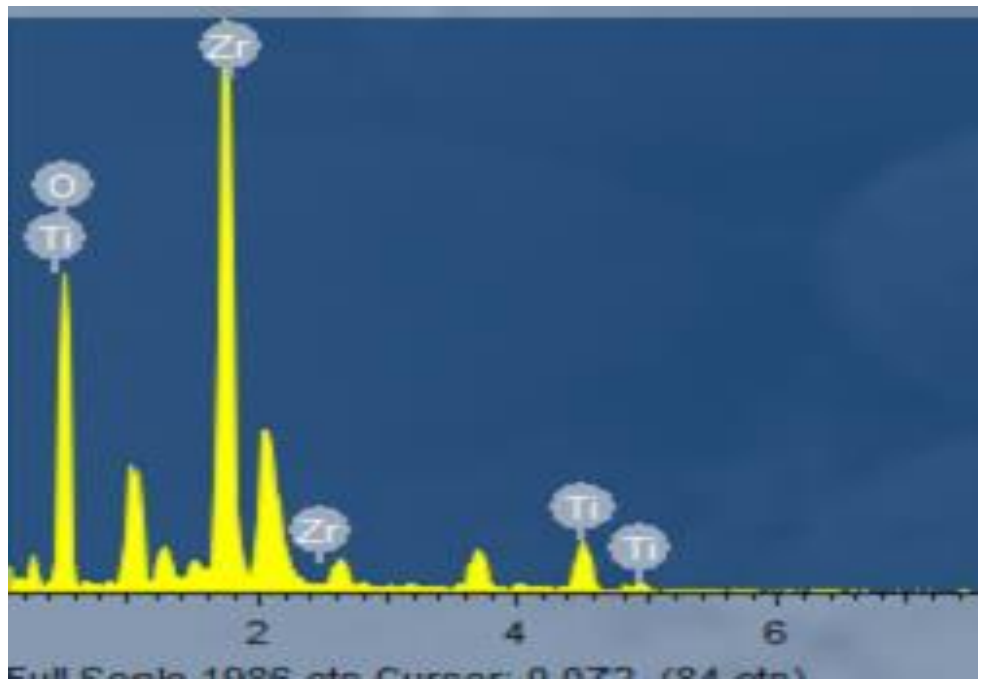

Figure 2. EDX Spectrum of $\mathrm{ZrTiO} 2$ Thin film. 


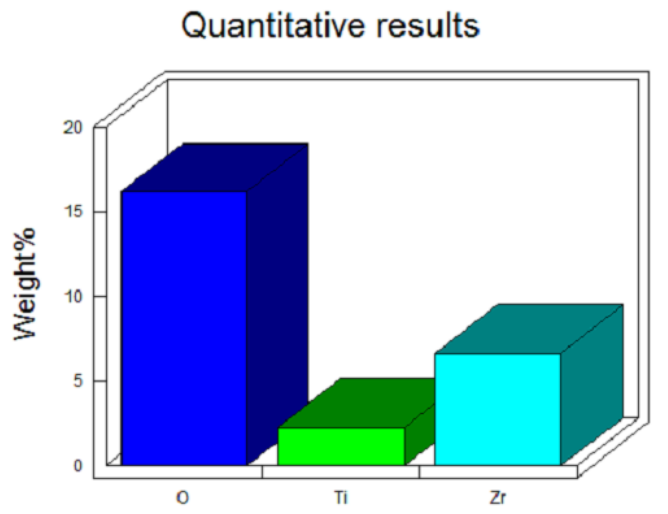

Figure 3. Bar-Chart of ZrTiO2 Thin film.

Table 1. Elemental composition of $\mathrm{ZrTiO}_{2}$

\begin{tabular}{l|c|c} 
Element & Weight\% & Atomic\% \\
\hline O K & 16.2 & 89.34 \\
\hline Ti K & 2.28 & 4.20 \\
\hline Zr K & 6.68 & 6.46 \\
\hline Totals & 25.16 & -
\end{tabular}

Figure 4 shows the FTIR spectrum of $\mathrm{ZrTiO}_{2}$ films. The $\mathrm{X}$-axis represents the wavelength $\left(\mathrm{cm}^{-1}\right)$, and $\mathrm{Y}$-axis represents light absorbance passing through the sample. The band at $2744 \mathrm{~cm}^{-1}$ indicating a vibration $\mathrm{Zr}-\mathrm{O}$ bond. The bond at $3700 \mathrm{~cm}^{-1}$ corresponds to the vibration of the $\mathrm{Si}-\mathrm{O}$ bond. The band stretching in the range $2060-3600 \mathrm{~cm}^{-1}$ was attributed to a surface hydroxyl group's symmetrical vibration. A broad absorption seen in the range 3100$3700 \mathrm{~cm}^{-1}$ might be related to the stretching hydroxyl $(\mathrm{O}-\mathrm{H})$ group resulting from titanium isopropoxide hydrolysis. Carbon-based functionalization traces identified on pure $\mathrm{Zr}$ doped $\mathrm{TiO}_{2}$ surface may reflect between $1600-2100 \mathrm{~cm}^{-1}$. The band at $1640 \mathrm{~cm}^{-1}$ representing the O$\mathrm{H}$ bending mode of the absorbed water. The band at $2360 \mathrm{~cm}^{-1}$ is because of the absorbed water $\left(\mathrm{H}_{2} \mathrm{O}\right)$ molecules after sol-gel coating.

The bands in the range 950-400 $\mathrm{cm}^{-1}$ can be assigned to different stretching modes associated with metal oxides. In our case, the band may be attributed to the Ti-O bands in $\mathrm{Zr}$ doped TiO2 samples. The bands at $1242 \mathrm{~cm}^{-1}, 1111 \mathrm{~cm}^{-1}, 1035 \mathrm{~cm}^{-1}$, and $860 \mathrm{~cm}^{-1}$ correspond to Ti-OH's vibration mode. The band around $665 \mathrm{~cm}^{-1}$ was attributed to the vibration mode of the Ti-O-Ti bond; the most apparent peaks were observed at $443 \mathrm{~cm}^{-1}$, referring to the Ti-OTi stretching mode. FTIR spectrum of Figure 4 is enlarged and drawn in parts to show the low amplitude peaks clearly.

A search of the ICDD (International Centre for Diffraction Data) database of X-ray diffraction patterns enables the phase identification of a large variety of crystalline samples. The $\theta-2 \theta$ scan maintains these angles with the sample, detector, and X-ray source. Only those planes of atoms that share this normal will be seen in the $\theta-2 \theta$ scan. The inter-planar distance can be calculated from Bragg's law substituting $\lambda$ and $\theta$ values from the XRD results, $D_{\mathrm{p}}=0.94 \lambda / \beta \cos \theta$

Where $B=$ Line broadening in radius

$\lambda=$ wavelength of characteristic X-rays $(1.540 \mathrm{~A})$

$\theta=$ Bragg's angle,

$\mathrm{Dp}=$ Average crystal size 

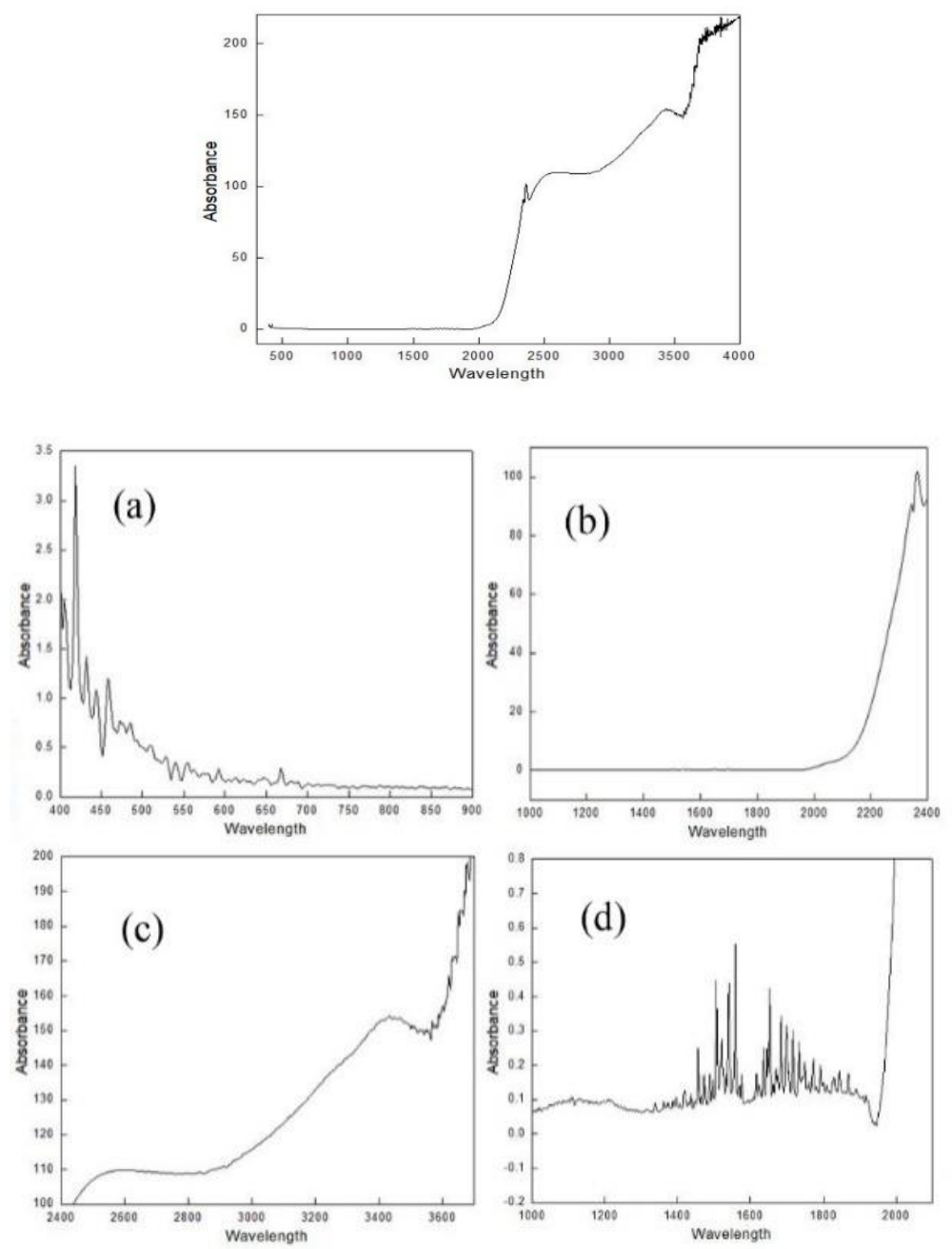

Figure 4. FTIR spectrum of $\mathrm{ZrTiO}_{2}$.

The XRD pattern of titanium doped $\mathrm{ZrO}_{2}$ in Figure 5 shows a smooth line without any specific peaks. The absence of peaks indicates the amorphous nature of the material. The amorphous nature is more suitable for MOS capacitor applications. XRD patterns of $\mathrm{ZrTiO}_{2}$ thin film are the same for 4000, 5000, and $6000 \mathrm{rpm}$, and crystalline size is $22 \mathrm{~nm}$.

C-V measurements carried out by using the Agilent (model:1500A) Semiconductor Device Analyzer taken at $100 \mathrm{kHz}$ are plotted in Figure 6. Three regions of the $\mathrm{C}-\mathrm{V}$ graph, namely accumulation, depletion, and inversion, formed due to variation in carrier concentrations at the interface with bias voltage, are distinctly visible. The maximum accumulated capacitance is found to be $511 \mathrm{pF}$ at $4000 \mathrm{rpm}, 132 \mathrm{pF}$ at $5000 \mathrm{rpm}$, and $183 \mathrm{pF}$ at $6000 \mathrm{rpm}$. The dielectric constant calculated from the C-V plot was 37.6, 32.1, and 29.1, respectively, for samples at spin rates of $4000 \mathrm{rpm}, 5000 \mathrm{rpm}$, and $6000 \mathrm{rpm}$.

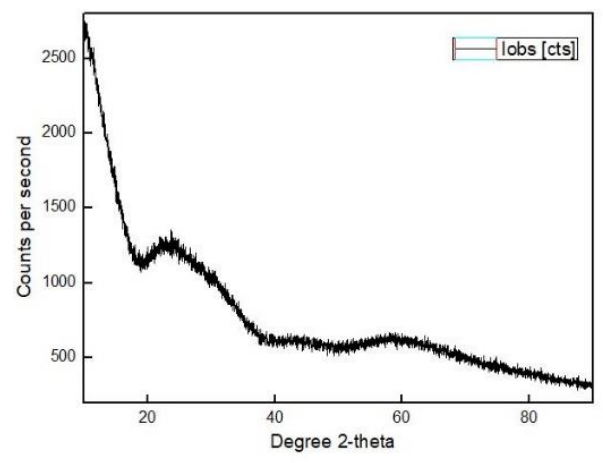

Figure 5. XRD image of ZrTiO2 Thin Film. 


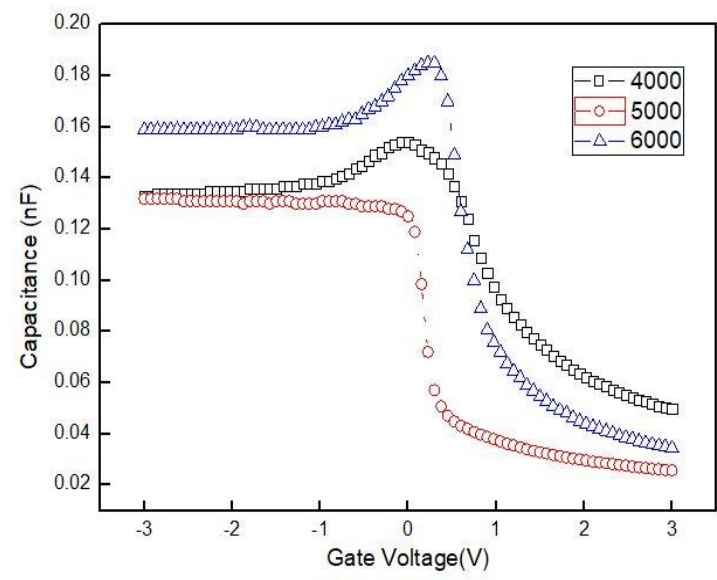

Figure 6. C-V analysis of $\mathrm{ZrTiO}_{2}$ thin film.

This dielectric constant variation is attributed to the variations of oxide layer thickness because of different spin rates adopted. Oxide layer thickness varies from $44 \mathrm{~nm}$ to $40 \mathrm{~nm}$. The maximum gate leakage current is $152 \mathrm{nA}$ for $4000 \mathrm{rpm}, 26.7 \mathrm{nA}$ for $5000 \mathrm{rpm}$, and $369 \mathrm{nA}$ for $6000 \mathrm{rpm}$, which is lower than that of the existing literature and consistent for the use in MIS structures. All the parameters are shown in table number 2. Overshoot in the CV graph is observed against the $6000 \mathrm{rpm}$ curve because of the excessive trap charges available at the interface.

The conductivity of the prepared $\mathrm{ZrTiO}_{2}$ solution is measured using an electrical conductivity meter. We aim to prepare a solution, which is a purely insulating material. Generally, the insulating material's conductivity value is greater than or equal to $10^{-8} \mathrm{~s} / \mathrm{cm}$. The conductivity value of the prepared $\mathrm{ZrTiO}_{2}$ solution is $10^{-8} \mathrm{~S} / \mathrm{cm}$. Electrical Conductivity Meter gives only the magnitude and not a graph. Table 2 shows a summary of the results.

Table 2. Result summary.

\begin{tabular}{l|l|l|l|l|l|l|l|l} 
& $\begin{array}{l}\text { Thickness } \\
\left(\boldsymbol{t}_{\text {ox }}\right)\end{array}$ & $\begin{array}{l}\text { Refractive } \\
\text { Index }(\boldsymbol{n})\end{array}$ & $\begin{array}{l}\text { Maximum } \\
\text { Accumulation } \\
\text { Capacitance Cmax }\end{array}$ & $\begin{array}{l}\text { Dielectric } \\
\text { constant }(\boldsymbol{k})\end{array}$ & EOT & $\begin{array}{l}\text { Flatband } \\
\text { Voltage } \\
\left(\boldsymbol{V}_{\text {fb }}\right)\end{array}$ & Bandgap & $\begin{array}{l}\text { Maximum } \\
\text { Leakage } \\
\text { Current at }+2 \text { V V }\end{array}$ \\
\hline $4000 \mathrm{rpm}$ & $44 \mathrm{~nm}$ & 1.86562 & $1.52 \mathrm{E}-10$ & 37.6 & $4.5 \mathrm{~nm}$ & $0.375 \mathrm{~V}$ & 4.2 & $152 \mathrm{nA}$ \\
\hline $5000 \mathrm{rpm}$ & $41.203 \mathrm{~nm}$ & 1.77468 & $1.32 \mathrm{E}-10$ & 32.1 & $5 \mathrm{~nm}$ & $0.1 \mathrm{~V}$ & 4.3 & $26.7 \mathrm{nA}$ \\
\hline $6000 \mathrm{rpm}$ & $40.381 \mathrm{~nm}$ & 1.27867 & $1.83 \mathrm{E}-10$ & 29.1 & $5.4 \mathrm{~nm}$ & $-0.3 \mathrm{~V}$ & 4.4 & $369 \mathrm{nA}$
\end{tabular}

\section{Conclusions}

The primary focus of this work is to study the electrical characteristics of the high-k dielectric layer of Zirconium Titanate $\left(\mathrm{ZrTiO}_{2}\right)$ prepared using Sol-Gel based spin coating technique. Initially, titanium doped zirconium dioxide solution is prepared using the Sol-Gel method; after preparation of the solution, it is tested for conductivity, which is $10^{-8}$ siemens $/ \mathrm{cm}$. This confirms the prepared material's suitability to be used as a dielectric material. The solution is then deposited on glass substrates and $\mathrm{p}-\mathrm{Si}(100)$ using the spin coating method at varying speeds of 4000, 5000, and $6000 \mathrm{rpm}$. The films are characterized for their chemical, structural and electrical properties. From the XRD graph, it is known that the prepared films are purely amorphous. From the FESEM results, the thin film morphology is found to be smooth, and a uniform deposition had taken place. From the EDX results, the $\mathrm{Zr}$ :Ti ratio is shown as 1:2. The thickness of the thin film is obtained by characterizing the film using a spectroscopic ellipsometer.

Film thicknesses were 44, 41, and $40 \mathrm{~nm}$ respectively for 4000, 5000, and $6000 \mathrm{rpm}$ spin rates. Thus it satisfies the relation, i.e., the spin speed is inversely proportional to the film 
thickness. Obtained Leakage currents are much lower than the reported gate leakage current density. The values obtained from Agilent 1500A Semiconductor Device Analyzer are $152 \mathrm{nA}$, $26.7 \mathrm{nA}$, and $369 \mathrm{nA}$, respectively, for different spin rates. Maximum accumulation capacitance $\left(\mathrm{C}_{\max }\right)$ values are $15.2 \mathrm{nF}, 13.2 \mathrm{nF}$ and $18.3 \mathrm{nF}$. Calculated dielectric constant(k) values from the accumulation capacitance are 37.6, 32.1, and 29.1, respectively, for three different spin rates. These values are greater than the reported values.

\section{Future Scope}

The deposited films can be annealed at various temperatures like $400^{\circ} \mathrm{C}, 500^{\circ} \mathrm{C}$, and $600^{\circ} \mathrm{C}$ to analyze the MOSCAP device properties like dielectric constant, leakage current, and equivalent oxide thickness based on the changes in crystal orientation of the material (phase formation).

\section{Funding}

This research received no external funding.

\section{Acknowledgments}

This research has no acknowledgment.

\section{Conflicts of Interest}

The authors declare no conflict of interest.

\section{References}

1. Zhang, Q.; Guodong, X.; Wenwen, X.; Ji, Z.; Sumei, W. Low-temperature solution-processed high-k ZrTiO dielectric films for high-performance organic thin film transistors. Applied Physics 2015, 79, $182-911$. https://doi.org/10.1016/j.synthmet.2015.10.011.

2. Xia, D.Q.; He, G.; Liu,M.; Gao, J.; Jiang, S.S.; Li, D.; Zhang, M.; Liu, Y.M.; Lv, J.G.; Sun, Z.Q. Modification of optical and electrical properties of sol-gel-derived $\mathrm{TiO} 2$-doped $\mathrm{ZrO} 2$ gate dielectrics by annealing temperature. Journal of Alloys and Compounds 2016, 688, 252-259, https://doi.org/10.1016/j.jallcom.2016.07.179.

3. Rabah, B.; Hanene, B. Synthesis, Characterization and properties of Zirconium oxide doped Titanium oxide thin films obtained via sol-gel process. Heat Treatment Conventional Applications 2015, 95, 22-26, https://doi.org/10.5772/51155.

4. Kondaiah, P.; Jagadeesh Chandra, S.V.; Fortunato, E.; Jong, C.H.; Mohan Rao, G.; Reddy, D.V.R.K.; Uthanna, S. Substrate temperature influenced $\mathrm{ZrO} 2$ films for MOS devices. Surface and Interface Analysis 2020, 52, 541-546, https://doi.org/10.1002/sia.6775.

5. Kumar,nM.; Jagadeesh Chandra, S.V.; Ju, M.; Dutta, S.; Ramana, C.H.V.V.; Qamar, H.S.; Park, J.; Kim, Y.; Cho, Y.H.; Cho, E.C.; Yi, J. Influence of ultra-thin Ge3N4 passivation layer on structural, interfacial and electrical properties of $\mathrm{HfO} 2 / \mathrm{Ge}$ metal oxide semiconductor devices. Journal of Nanoscience and Nanotechnology 2020, 20, 1039-1045, https://doi.org/10.1166/jnn.2020.16934.

6. Kumar, M.; Jagadeesh Chandra, S.V.; Ju, M.; Dutta, S.; Swagata, P.; Sanyal, S.; Pham, D.P.; Qamar, S.H.; Kim, Y.; Park, J.; Cho, Y.H.; Cho, E.C.; Yi, J. Effects of post deposition annealing atmosphere on interfacial and electrical properties of $\mathrm{HfO} 2 / \mathrm{Ge} 3 \mathrm{~N} 4$ gate stacks. Thin Solid Films 2019, 675, 16-22, https://doi.org/10.1016/j.tsf.2019.02.034.

7. Janardhanam, V.; Yun, H.J.; Jyothi, I.; Yuk, S.H.; Lee, S.N.; Won, J.; Choi, C.J. Fermi-level depinning in metal/Ge interface using oxygen plasma treatment. Applied Surface Science 2019, 463, 91-95, https://doi.org/10.1016/j.apsusc.2018.08.187.

8. Reddy, P.R.S.; Janardhanam, V.; Lee, H.K.; Shim, K.H.; Lee, S.N.; Reddy, V.R.; Choi, C.J. Schottky barrier parameters and low-freqency noise characteristics of $\mathrm{Au} / \mathrm{Ni}$ contact to n-type $\beta-\mathrm{Ga} 2 \mathrm{O} 3$. Journal of Electronic materials 2020, 49, 297-305, https://doi.org/10.1007/s11664-019-07728-z. 
9. Rashid, H.; Rahman, K.S.; Hossain, M.I.; Nasser, A.A.; Alharbi, F.H.; Akhtaruzzaman, M.; Amin, N. Physical and electrical properties of molybdenum thin films grown by DC magnetron sputtering for photovoltaic application. Results in Physics 2019, 14, https://doi.org/10.1016/j.rinp.2019.102515.

10. Shukor, A.H.; Alhattab, H.A.; Takano, I. Electrical and optical properties of copper oxide thin films prepared by DC magnetron sputtering. Journal of Vacuum Science \& Technology 2020, B38, https://doi.org/10.1116/1.5131518.

11. Dewi, R.K.; Zuhdi, Z.; Hussain, T.S.L. Analysis of optical and electrical properties of thin films Ba1xSrxRiO3 (with $\mathrm{x}=0.1$ and $\mathrm{x}=0.6$ ). International Journal of Advanced Science and Technology 2020, 29, 365-377, http://sersc.org/journals/index.php/IJAST/article/view/3922.

12. Chen, X.; Yu, Z.; Guan, X.; Hao, Z. Facile synthesis of Solution-processed Silica and Polyvinyl phenol hybrid dielectric for flexible organic transistors. Nanomaterials 2020, 10, https://doi.org/10.3390/nano10040806.

13. Devesa, S.; Teixeira, S.S.; Rooney, A.P.; Graca, M.P.; Cooper, D.; Costa, L.C. Structural, morphological and dielectric properties of ErNbO4 prepared by the Sol-Gel method. Journal of Physics and Chemistry of Solids 2020, https://doi.org/10.1016/j.jpcs.2020.109619.

14. Hwang, D.; Shin, S.; Kim, H.; Lee, T. A study on improvement of optical/electrical properties of Indium-tin oxide thin films prepared by Sol-Gel process. SAE Technical paper 2019, https://doi.org/10.4271/2019-010187.

15. Chandra Sekhar, M.; Kondaiah, P.; Jagadeesh Chandra, S.V.; Mohan Rao, G.; Uthanna, S. Effect of substrate bias voltage on the structure, electric and dielectric properties of $\mathrm{TiO} 2$ thin films by $\mathrm{DC}$ magnetron sputtering. Applied Surface Science 2011, 258, 1789-1796, https://doi.org/10.1016/j.apsusc.2011.10.047.

16. Zhu, H.E.; Zhao, B.; Liu, X.; Kang, J.; Han, R. Fabrication and Electrical Properties of Titanium Oxide by Thermally Oxidizing Titanium on Silicon. Chinese Journal of Semiconductors 2002, 23, 337-341.

17. Chandra Sekhar, M.; Kondaiah, P.; Mohan Rao, G.; Jagadeesh Chandra, S.V.; Uthanna, S. Post-deposition annealing influenced structural and electrical properties of $\mathrm{Al} / \mathrm{TiO}_{2} / \mathrm{Si}$ gate capacitors. Super lattices and Microstructures 2013, 62, 68-80, https://doi.org/10.1016/j.spmi.2013.07.001.

18. Sue-Min, C.; Ruey-An, D. Inter band Transitions in Sol-Gel-Derived $\mathrm{ZrO}_{2}$ Films under Different Calcination Conditions. American Chemical Society 2007, 49, 501-520. https://doi.org/10.1021/cm070606n.

19. Ramalingam, S. Synthesis of nanosized Titanium dioxide by Sol-Gel technique. International journal of Innovative Technology and Exploring Engineering (IJITEE) 2019, 9, 732-735, https://doi.org/10.35940/ijitee.B1174.1292S219.

20. Ganesh, S.; Sang, Y.K. High-k polymer nanocomposite materials for technological applications. Applied sciences 2020, 10, 4249-4267, https://doi.org/10.3390/app10124249.

21. Akkaya, A.; Boyarbay, B.; Cetin, H.; Yildizli, K.; Ayyildiz, E. A study on the electronic properties of SiOxNy/p-Si interface. Silicon 2018, 10, 2717-2725, https://doi.org/10.1007/s12633-018-9811-6.

22. Amit, K.; Shailey, S.; Shilpi, A.; Rajendra, P.B.; Sharma, A.K. Influence of Synthetic Approach of SiO2ZrO2 Materials. Catal. Sustain. Energy 2018, 5, 34-40, https://doi.org/10.1515/cse-2018-0005.

23. Venkataiah, S.; Jagadeesh Chandra, S.V.; Chalapathi, U.; Ramana, C.H.V.V.; Uthanna, S. Oxygen partial pressure influenced stoichiometry, structural, electrical and optical properties of DC reactive sputtered hafnium oxide films. Surface and Interface Analysis 2020, 1-9, https://doi.org/10.1002/sia.6902.

24. Ogugua, S.N.; Martin, O.N.; Swart, H.C. Latest development on pulsed laser deposited thin films for advanced luminescence applications. Coatings $\mathbf{2 0 2 0}$ 10, 1078-1100, https://doi.org/10.3390/coatings10111078.

25. Xin, W.; Ghosh, S.K.; Mohajer, M.A.; Hua, Z.; Yongqiang, L.; Xiaxiao, H.; Jiyu, C.; Min, Z.; Xiangbo, M. Atomic layer deposition of Zirconium oxide thin films. Journal of Materials Research 2020, 35, 804-812, https://doi.org/10.1557/jmr.2019.338.

26. Oluwabi, A.T.; Juma, A.O.; Acik, I.O.; Arvo, M.; Malle, K. Effect of Zr doping on the structural and electrical properties of spray deposited TiO2 thin films. Proceedings of the Estonian Academy of Sciences 2018, 67, https://doi.org/10.3176/proc.2018.2.05.

27. Kayani, Z.N.; Anum, K.; Zeb, S.; Saira, R.; Shahzad, N. Probe of ZrTiO2 thin films with TiO2-ZrO2 binary oxides deposited by dip coating technique. Journal of Photochemistry and Photobiology B: Biology 2018, 183, 357-366, https://doi.org/10.1016/j.jphotobiol.2018.04.051.

28. Rajvee, M.H.; Kumar, P.R.; Srinivasarao, Y. Effect of pre synthesis sintering on bandgap of CeZrO4 nano crystalline powders prepared through high energy ball milling for high $\mathrm{k}$ dielectric thin films. 2018 Conference on Signal Processing And Communication Engineering Systems (SPACES) 2018, https://doi.org/10.1109/SPACES.2018.8316334. 